\title{
LAS FUNCIONES ADMINISTRATIVAS Y JURISDICCIONALES Y LA PROTECCIÓN DE LOS DERECHOS DE LOS CONSUMIDORES. ANÁLISIS DE LA SENTENCIA DEL Tribunal Constitucional bajo el Rol N 4012-17
}

[The administrative and jurisdictional functions and the protection of the rights of consumers. Analysis of the judgment of the Constitutional Tribunal under Role $\mathrm{N}^{\circ}$ 4012-17]

\author{
AleXander Espinoza* \\ JHEnNy Rivas Alberti* ${ }^{* *}$
}

Recibido el 1 de abril de 2019 y Aprobado el 24 de abril de 2019.

\section{INTRODUCCIÓN}

Mediante sentencia del 18 de enero de 2018 el Tribunal Constitucional se pronunció acerca del Proyecto de ley, que modifica la Ley $\mathrm{N}^{\circ} 19.496$, sobre Protección de los Derechos de los Consumidores. El Tribunal analizó la atribución de facultades al Servicio Nacional del Consumidor, para imponer sanciones de multa a los proveedores, constituirse en instancia de mediación, así como para ordenar el cese de las conductas infractoras, la restitución de los cobros que le parezcan improcedentes, además de adoptar indeterminadas medidas para evitar supuestas infracciones futuras.

Las normas mencionadas fueron objeto de control de constitucionalidad, a la luz de lo dispuesto en los artículos $19, \mathrm{~N}^{\circ} 3$, inciso sexto, y 76, inciso primero, de la Carta Fundamental, desde el punto de vista del

* Doctor iuris Universität Passau, Alemania. Docente de la Universidad Autónoma de Chile, Chile. Dirección postal: Universidad Autónoma de Chile. Sede Talca. Facultad de Derecho. Piso 5. 5 Poniente 1670, Talca, Chile. Dirección electrónica: alexander.espinoza@uautonoma.cl.

** Doctora en Derecho por la Universidad de Zaragoza, España. Docente de la Universidad Autónoma de Chile, Chile. Sede Talca. Dirección postal: Universidad Autónoma de Chile. Sede Talca. Facultad de Derecho. Piso 5. 5 Poniente 1670, Talca. Chile. Dirección electrónica: jhenny.rivas@uautonoma.cl. 
régimen de separación de funciones ${ }^{1}$, así como, en base a la garantía de un proceso justo y racional, prevista en el artículo $19, \mathrm{~N}^{\circ} 3^{\circ}$, inciso sexto, de la Constitución, en cuanto a la separación orgánica de la investigación y la sanción ${ }^{2}$. Finalmente, el Tribunal revisó si se encontraban dadas las condiciones que garantizaran la independencia e imparcialidad, como componentes de todo proceso justo y racional ${ }^{3}$.

En el presente estudio nos proponemos determinar cuáles son los criterios que permiten clasificar una función de naturaleza administrativa o jurisdiccional. En base a tales criterios, analizaremos las competencias atribuidas en el proyecto de ley al Servicio Nacional del Consumidor.

Delimitado de tal forma el objeto del trabajo, debemos advertir que no corresponde al mismo el análisis de las normas constitucionales de competencias del poder judicial, a la luz del principio de separación de funciones ${ }^{4}$. También dejaremos de lado el problema, de cuáles requisitos de independencia e imparcialidad les serían exigibles constitucionalmente, a los órganos administrativos en ejercicio de funciones jurisdiccionales 5 .

${ }^{1}$ TC Rol No 4012-17-CPR de 18 de enero de 2018, 33ㄹ disponible [en línea]: http://www.tribunalconstitucional.cl/wp/ver.php?id=3621.

${ }^{2}$ TC Rol No 4012-17-CPR, cit. (n 1), 33 .

${ }^{3}$ TC Rol No 4012-17-CPR, cit. (n 1), 38 .

${ }^{4}$ Véase al respecto, Bordalí Salamanca, Andrés, La doctrina de la separación de poderes y el poder judicial chileno, en Revista de Derecho (Valparaíso) 30 (2008), pp. 185-219.

${ }^{5}$ Véase al respecto, Moraga Klenner, Claudio, ¿ Existen en Chile procedimientos administrativos que presentan, también, una naturaleza jurisdiccional?, en Derecho PUCP 68 (2011), p. 235; CEA EgAÑa, José Luis, La igual proteccion de los derechos, en Revista Chilena de Derecho 9 (1982), p. 521.; Boettiger Philipps, Camila, El derecho administrativo sancionador en la jurisprudencia del Tribunal Constitucional, en Revista Actualidad Jurídica 20 (2009), p. 580; Letelier, Raúl, Garantías penales y sanciones administrativas, en Polit. crim 12 (2017), 24, pp. 622-689; VAN WEEZEL, Alex, Sobre la necesidad de un cambio de paradigma en el derecho sancionatorio administrativo, en Politica criminal 12 (2017), 24, pp. 997-1043; ZÚNIGA URBINA, Francisco, Autonomías constitucionales e instituciones contramayoritarias (a propósito de las aporías de la "democracia constitucional"), en Ius et Praxis 13 (2007), 2, pp. 223-244. Bordalí Salamanca, Andrés, La independencia de los jueces en la aplicación de la ley dentro de la organización judicial chilena, en Revista Chilena de Derecho 40 (2013), 2, pp. 609-634; Bordalí Salamanca, Andrés, Organización judicial en el derecho chileno: Un poder fragmentado, en Revista Chilena de Derecho 36 (2009), 2, pp. 215-244; Gordillo, Agustín, Tratado de derecho administrativo y obras selectas: Parte general (Buenos Aires, Fundación de Derecho Administrativo, 2017); ILÜBBERT Álvarez, Valeria, El derecho a no ser juzgado por comisiones especiales: análisis crítico de jurisprudencia, en Revista de Estudios de la Justicia 15 (2011), pp. 87-105 y 93. Acerca de la imparcialidad e independencia del Director Regional del Servicio de Impuestos Internos, EnTeiche Rosales, Nicolás. Ley No 20.322: avances y desafíos respecto de la 


\section{CRiterios De DELIMITACiÓN}

Para distinguir entre una función administrativa y jurisdiccional tomaremos como punto de partida el método residual, según el cual, corresponde a la administración pública las materias distintas a las funciones legislativas y jurisdiccionales, así como su función de proteger los intereses generales. Encontraremos que la función jurisdiccional presenta características diversas según se trate de controversias de derecho civil, penal o de derecho público. Desestimaremos brevemente las controversias de derecho penal o de derecho público, para centrar nuestra atención en las causas civiles, por ser el punto de comparación más cercano a los conflictos entre consumidores y proveedores.

\section{Las funciones administrativas}

La determinación del ámbito de aplicación del derecho administrativo se remonta al método residual empleado a fines del siglo XIX por Otto Mayer, en el sentido de identificar los elementos característicos de la función legislativa y jurisdiccional, mientras que el resto de las funciones serían calificadas, por defecto, como una función administrativa ${ }^{6}$. Para Mayer, la jurisdicción es la actividad del estado destinada al mantenimiento del ordenamiento jurídico, a través del poder del estado. Con la separación entre el poder judicial y el ejecutivo, quedó reservada al primero la justicia civil y penal. Toda otra actividad sujeta a la ley pertenecía a la administración ${ }^{7}$.

Este criterio se ha mantenido casi inalterado en el derecho administrativo alemán. ${ }^{8}$ El Tribunal Federal Administrativo ha señalado que, la descripción de los elementos típicos de la administración no ha sido capaz de abarcar toda su diversidad, por lo que debe emplear un método que substraiga el ámbito de la administración, simplemente al delimitarlo frente a las demás funciones del estado?.

En Chile, ha precisado el Tribunal Constitucional que, las funciones

inspección y sanción de infracciones administrativas en materia tributaria, en Revista Actualidad Jurídica 26 (2012), pp. 259-278.

${ }^{6}$ MaYer, Otto, Deutsches Verwaltungsrecht (Leipzig, Verlag von Duncker \& Humblot, 1895), I, p. 9.

${ }^{7}$ MAYer, cit. (n. 6), p. 6.

${ }^{8}$ VON MüNCH, Ingo, Verwaltung und Verwaltungsrecht im demokratischen und sozialen Rechtsstaat, en ERICHSEN - MARTENS (coords.), Allgemeines Verwaltungsrecht (Walter de Gruyter GmbH \& Co. KG, 2016), p. 3, quien propone distinguir además entre las funciones de la administración y el gobierno.

${ }^{9}$ BVerwG, Urteil vom 03.11.2011 - 7 C 3.11, disponible [en líea]: https:// www.bverwg.de/031111U7C3.11.0], Abs. 13; WienbracKe, Mike, Allgemeines Verwaltungsrecht CF (Müller GmbH, 2012), p. 2. 
administrativas apuntan a satisfacer necesidades públicas de manera regular y continua ${ }^{10}$. Sin embargo, se trata de una definición tan amplia, que obliga a emplear el método de delimitación negativa ${ }^{11}$. En todo caso, como un elemento material que caracteriza la función administrativa encontramos la defensa de los intereses generales ${ }^{12}$, como la contrapartida de la resolución de conflictos entre intereses individuales, que define la función jurisdiccional ${ }^{13}$.

Como veremos más adelante, no se trata de dos situaciones perfectamente opuestas, sino que contienen elementos mixtos. El interés general siempre aparece como un bien jurídico protegido, aún cuando en el caso de conflictos intersubjetivos se plantea como una protección refleja o secundaria.

\section{Exclusión de conflictos de derechos subjetivos públicos}

Resulta claro que la función jurisdiccional presenta características muy distintas si se trata de una causa civil, penal, contencioso administrativa o constitucional. La diferencia esencial puede encontrarse en el tipo de relación jurídica. Los conflictos de intereses que son objeto de una función jurisdiccional pueden producirse entre particulares, entre éstos y el Estado y entre los poderes públicos ${ }^{14}$. A ésta enumeración deben agregarse las

${ }^{10}$ TC Rol No 2865 de 30 de Diciembre de 2015, disponible [en línea]: https:// www.tribunalconstitucional.cl/ver2.php?id=3217, 35\%; Rol No 3594-17 de 31 de Mayo de 2018, ID vLex: 727329889, disponible [en línea]: http://jurisprudencia. vlex.cl/vid/727329889, 33.

${ }^{11}$ Silva Cimma, Enrique, Derecho Administrativo chileno y comparado. Introducción y fuentes (5a edición, Santiago, Editorial Jurídica de Chile, 2009), p. 26. Este método ha sido empleado por el Tribunal Constitucional al analizar la naturaleza jurídica de los actos de retención de la Tesorería, en TC Rol No 2865, cit. (n 10), 35; Rol No 3594-17, cit. (n. 10), 33․

${ }^{12}$ Moraga, cit (n. 5), p. 235; Colombo Campbell, Juan, La Jurisdicción en el Derecho Chileno (Santiago, Editorial Jurídica de Chile, 1991), p. 45.

${ }^{13}$ En el caso del ejercicio de la potestad informativa del Tribunal de Defensa de la Libre Competencia, el Tribunal Constitucional observó que en cuanto al fundamento y objetivo, ésta dice relación con la protección del bien jurídico de la libre competencia en los mercados monopólicos y no dirime propiamente un conflicto de relevancia jurídica, por lo que debía ser calificado como una competencia de carácter administrativo. TC Rol No 1448-09 de 7 de septiembre de 2010, disponible [en línea]: https://www.tribunalconstitucional.cl/ver2.php?id=1522, $20^{\circ}$ y $21^{\circ}$.

${ }^{14}$ TC Rol 165-93 de 19 de enero de 1993, disponible [en línea]: https://www. tribunalconstitucional.cl/ver2.php?id=449, $3^{\circ}$. También en este sentido, AlCALÁZamora y CaStillo, Niceto, Notas relativas al concepto de jurisdicción, en Estudios de teoría general e historia del proceso (1945-1972) (México D. F., Universidad Nacional Autónoma de México, 1992), I, p. 44; Moraga, cit (n. 5), p. 243. 
relaciones jurídico-penales. Por tal motivo, la calificación de una función administrativa o jurisdiccional debe realizarse necesariamente, tomando en consideración las características de las diversas funciones jurisdiccionales.

La noción de "conflictos de intereses de relevancia jurídica" ha sido definida como la actividad capaz de establecer o afectar derechos de terceros. A través de este criterio, el Tribunal Constitucional ha declarado que la resolución del Ministro de Transportes y Telecomunicaciones que otorga o deniega una concesión o un permiso de telecomunicaciones, constituye el ejercicio de funciones jurisdiccionales. ${ }^{15}$ Según el tribunal, en el concepto "causas civiles" a que se refiere el artículo 73 de la Constitución, se deben incluir todas aquellas controversias jurídico administrativas que afectan los derechos de las personas ${ }^{16}$.

Sin embargo, estimamos que se trata de una definición demasiado amplia. Una interpretación de tal naturaleza podría llevar a considerar por ejemplo como una función jurisdiccional el procedimiento de concursos públicos para el ingreso a la carrera funcionaria, debido a que constituye una actividad capaz afectar derechos de los demás aspirantes. Sin embargo, se trata claramente de una función administrativa, regulada por el artículo 38 de la Constitución Política ${ }^{17}$.

La relación jurídica, que se configura entre los interesados a obtener una concesión o un permiso de telecomunicaciones y el Ministerio de Transportes y Telecomunicaciones, o entre los aspirantes a la carrera funcionaria y el estado, tiene una diferencia sustancial con respecto a la controversia civil. En las primeras se trata de relaciones jurídicas conformadas por derechos subjetivos públicos. La pretensión de los interesados a obtener un acto administrativo favorable, se basa en un derecho subjetivo, cuyo deudor no es el competidor, sino el estado, en la forma de un derecho a recibir un trato igualitario. Por su parte, la pretensión de las partes en una controversia civil se encuentra dirigida a exigir determinada conducta de otro particular.

De acuerdo con lo anterior debemos incorporar a la noción de "con-

${ }^{15 T C}$ Rol No 176 de 22 de noviembre de 1993, disponible [en línea]: https:// www.tribunalconstitucional.cl/ver2.php?id=440, $3^{\circ}$.

${ }^{16}$ TC Rol No 176, cit. (n. 15), 60. Desde el punto de vista del principio de imparcialidad, véase Bordali Salamanca, Andrés, El derecho fundamental a un tribunal independiente e imparcial en el ordenamiento jurídico chileno, en Revista de Derecho de la Pontificia Universidad Católica de Valparaiso 33 (2009), pp.263-302.

17 TC Rol No 4847-18 de 19 de julio de 2018, disponible [en línea]: https:// www.tribunalconstitucional.cl/ver2.php?id=3905], 7o; TC Rol 4945-18 de 12 de julio de 2018, 6º [visible en internet: https://www.tribunalconstitucional.cl/ver2. php?id=3902. 
flictos de intereses de relevancia jurídica" en controversias civiles, un elemento adicional que permitirá distinguirlo adecuadamente de la función administrativa. La función jurisdiccional civil consiste entonces en la resolución de conflictos de intereses de relevancia jurídica, de derechos subjetivos entre particulares y no de derechos subjetivos frente al estado ${ }^{18}$. Se trata, de la función de resolver la confrontación de pretensiones y resistencias o un conflicto intersubjetivo de intereses ${ }^{19}$, entre particulares, a diferencia de la función administrativa, orientada a una valoración de los intereses generales ${ }^{20}$.

\section{La delimitación entre sanciones penales y administrativas}

En el derecho comparado, el Tribunal Constitucional de Alemania ha precisado que la competencia de los órganos de la administración pública, para imponer sanciones pecuniarias no constituye una materia penal, sino simple derecho administrativo ${ }^{21}$. También ha precisado que, la norma penal contiene un juicio de desvalor ético-social sobre la conducta sancionada, con el objeto de preservar los valores elementales de la vida en sociedad, mientras que las contravenciones se refieren a ciertos situaciones de menor gravedad $^{22}$. Pero sólo la sanción criminal corresponde al derecho penal; la pena es incorporada al registro de antecedentes penales y tiene el valor de una "condena previa". Las multas en el procedimiento de contravenciones carecen de la "seriedad de la pena"23. La delimitación entre ambas, tomando en consideración la diversidad de convicciones sobre la valoración de la conducta, corresponde en todo caso, al legislador ${ }^{24}$.

Un criterio similar ha sido sostenido por el Tribunal Constitucional.

${ }^{18}$ Con respecto a la función jurisdiccional en el contencioso-administrativo, TC Rol No 616-06 de 6 de septiembre de 2007, disponible [en línea]: https://www. tribunalconstitucional.cl/ver2.php?id=93, 25\%.

${ }^{19}$ BORDALí, cit. (n. 5).

${ }^{20}$ Ferrajoli, Luigi, El papel de la función judicial en el Estado de Derecho. Jurisdicción y argumentación en el Estado constitucional de derecho, en Carbonell, Miguel, et. al. (coord.), Jurisdicción y argumentación en el estado constitucional de derecho (México D. F., Universidad Nacional Autónoma de México, Instituto de Investigaciones Jurídicas, 2005), p. 88; GonzÁlez Álvarez, Roberto, El nuevo paradigma de la garantía de la jurisdicción, en Ars Boni et Aequi 10 (2014), 1, pp. 119-150, p. 130.

${ }^{21}$ BVerfGE 8/197, Bußgeldverfahren disponible [en línea]: https://www. tribunalconstitucional.cl/ver2.php?id=3292.

${ }^{22}$ BVerfGE 27, 18/29 - Ordnungswidrigkeiten, disponible [en línea]: http:// www.servat.unibe.ch/dfr/bv027018.html.

${ }^{23}$ BVerfGE 22, 49/79 - Verwaltungsstrafverfahren, disponible [en línea]: http:// www.servat.unibe.ch/dfr/bv022049.html.

${ }^{24}$ BVerfGE 27, 18 /30 - Ordnungswidrigkeiten cit. (n 22). 
La posibilidad de que una determinada conducta sea sancionada por la vía administrativa o judicial es considerada una cuestión de política legislativa, cuya determinación queda entregada, en principio, al juicio de mérito que al respecto realice el legislador ${ }^{25}$. El ámbito de evaluación del legislador deriva además de la facultad de regulación de la actividad económica ${ }^{26}$. En todo caso, podemos precisar que, la separación entre sanciones penales y administrativas pasa por problemas relacionados con la naturaleza de los bienes jurídicos protegidos, la gravedad de la lesión y el tipo de sanciones, especialmente en cuanto a las penas privativas de libertad ${ }^{27}$.

En principio, la facultad de imponer sanciones pecuniarias no constitu-

${ }^{25}$ TC Rol No 725-2007 de 26 de junio de 2008, disponible [en línea]: https:// www.tribunalconstitucional.cl/ver2.php?id=962], 28; TC Rol №3106-16-CPR de 12 de julio de 2016, disponible [en línea]: https://www.tribunalconstitucional.cl/ ver2.php?id=3292, 15 ; CORDERO QuinZACARA, Eduardo, Sanciones administrativas y mercados regulados, en Revista de Derecho (Valdivia) 26 (2013), 1, pp. 119144, disponible [en línea]: http://mingaonline.uach.cl/scielo.php?script=sci_ arttext\&pid=S0718-09502013000100006\&lng=es\&nrm=iso, p. 128 y CORDERO Quinzacara, Eduardo, Concepto y naturaleza de las sanciones administrativas en la doctrina y jurisprudencia chilena, en Revista de Derecho (Coquimbo) 20 (2013), 1, pp. 79-103 disponible [en línea]: http://revistaderecho.ucn.cl/article/view/1929/1555, p. 96.

${ }^{26}$ TC Rol No 480-06 de 27 de junio de 2006, disponible [en línea]: https:// www.tribunalconstitucional.cl/ver2.php?id=616], $11^{\circ}$.

${ }^{27}$ Con respecto a lo dispuesto en el art. 20 del Código Penal, CS Rol No 7.3972012 de 16 de septiembre de 2013, Tercera Sala, 15º, disponible [en línea]: http:// basejurisprudencial.poderjudicial.cl. Véase además, TC Rol 244-96 de 26 de agosto de 1996, [visible en internet: https:/www.tribunalconstitucional.cl/ver2. php?id=926], 9. Cordero Quinzacara, Eduardo - Aldunate Lizana, Eduardo, Las bases constitucionales de la potestad sancionadora de la Administración, en Revista de Derecho (Valparaiso) 39 (2012), pp. 337-361, disponible [en línea]: https://dx.doi. org/10.4067/S0718-68512012000200013], p. 347; CORDERO, cit. (n. 25), p. 129 y CORDERO QUINZACARA, Eduardo Los principios que rigen la potestad sancionadora de la Administración en el derecho chileno, en Revista de Derecho (Valparaíso) 42 (2014), disponible [en línea]: https://dx.doi.org/10.4067/S0718-68512014000100012, p. 401; Van Weezel, Alex, Sobre la necesidad de un cambio de paradigma en el derecho sancionatorio administrativo, en Politica criminal 12 (2017), 24, disponible [en línea]: http://dx.doi.org/10.4067/S0718-33992017000200997]; Couso, Jaime, Autoría y participación en el derecho sancionatorio administrativo. Hacia una topografía del problema, en Ius et Praxis 24 (2018), 1, pp. 437-496, disponible [en línea]: http:// dx.doi.org/10.4067/S0718-00122018000100437. Véase también, con abundantes referencias a la jurisprudencia española, Cabrera Delgado, José Manuel, Duplicidad sancionadora en el ámbito administrativo y penal, en Avances en Supervisión Educativa 22 (2014), disponible [en línea]: http://avances.adide.org/index.php/ase/article/ download/52/51. En sentido contrario, LeTELIER, cit. (n. 5), p. 636, quien niega la diferencia ontológica entre ambas sanciones. 
ye en sí misma una función jurisdiccional. La jurisprudencia del Tribunal Constitucional ha establecido que la facultad de un órgano administrativo de aplicar, rebajar o condonar sanciones administrativas, se enmarca dentro de sus potestades administrativas sancionatorias, que no suponen ejercicio de jurisdicción ${ }^{28}$. Con ello, podemos considerar superado el criterio que afirmaba que la función de sancionar supone juzgar, lo cual pertenecería con exclusividad a los jueces ${ }^{29}$. El Tribunal Constitucional se ha referido además a las sanciones aplicadas por la autoridad sanitaria, señalando que puede resultar lícito que los órganos fiscalizadores puedan, previo al proceso judicial y en el ámbito administrativo, determinar la existencia de una infracción y la cuantía de una multa ${ }^{30}$. Mientras que las multas, constituyen las sanciones típicas del derecho administrativo, lo propio cabe aseverar de las penas privativas de libertad respecto del ámbito penal ${ }^{31}$.

Si bien lo anterior hubiera sido suficiente para excluir de nuestro estudio a la función jurisdiccional en causas penales, sin embargo, aún debemos referirnos a las facultades sancionatorias del Tribunal de Defensa de la Libre Competencia, en cuyo caso, nos encontramos con una situación de especial complejidad. Por una parte, el Tribunal Constitucional ha calificado a las infracciones a la legislación sobre protección de la libre competencia, como manifestación de una función jurisdiccional prevista en el artículo 76 de

${ }^{28}$ TC Rol No 725-2007, cit. (n. 25), 12º. Criterio reiterado en TC Rol No 766-2007 de 26 de junio de 2008, disponible [en línea]: http://www. tribunalconstitucional.cl/ver.php?id=963, $12^{\circ}$ y $13^{\circ}$; Rol No $1183-08$ de 8 de enero de 2009, disponible [en línea]: https:/www.tribunalconstitucional.cl/ver2. php?id=1077], 15; Rol № 3106-16-CPR de 12 de julio de 2016, disponible [en línea]: https://www.tribunalconstitucional.cl/ver2.php?id=3292, 170. También en este sentido, Román Cordero, Cristian, El castigo en el Derecho Administrativo, en Derecho y Humanidades 1 (2010), 16, disponible [en línea]: https://auroradechile. uchile.cl/index.php/RDH/article/download/16009/16524], p. 158. Con más referencias sobre la evolución jurisprudencial, BOETTIGeR, cit. (n. 5), p. 580.

${ }^{29}$ En ese sentido, Sото KLoss, Eduardo, Derecho Administrativo Penal. Notas para el estudio de la potestad sancionadora de la Administración, en Boletín de Investigaciones 44-45 (1979-1980), p. 95; Sото Kloss, Eduardo, Derecho administrativo. Temas fundamentales ( $3^{a}$ edición, Santiago, Thomson Reuters, 2012), pp. 495 ss.; ArósticA Maldonado, Iván, Algunos problemas del Derecho administrativo penal, en Revista de Derecho 71-81 (1987), disponible [en línea]: http://www.revistadederecho.com/pdf. php?id=2311, p. 72; Cea Egaña, José Luis, Derecho Constitucional Chileno (Santiago, Ediciones UC, 2008), II, p. 30.

${ }^{30}$ TC Rol No 792-07 de 3 de enero de 2008, disponible [en línea]: https://www. tribunalconstitucional.cl/ver2.php?id=728, $16^{\circ}$.

${ }^{31}$ TC Rol No 1518-09 de 21 de octubre de 2009, disponible [en línea]: https:// www.tribunalconstitucional.cl/ver2.php?id=1587, $5^{\circ}$. 
la Constitución Política ${ }^{32}$. Para ello tomó en consideración los elementos que caracterizan a la potestad punitiva administrativa en el sentido de "el poder con que actúan los órganos estatales no jurisdiccionales investidos de atribuciones para sancionar hechos ilícitos"33 y los elementos que definen una controversia penal, en el sentido que, se está en presencia de una función jurisdiccional cuando la acción u omisión de un individuo produce el quebrantamiento del ordenamiento jurídico, es decir, infringe la ley o norma reguladora de su conducta, sea permisiva, prohibitiva o imperativa ${ }^{34}$.

De tal forma, podríamos afirmar que, en criterio del Tribunal Constitucional, las sanciones impuestas por el Tribunal de Defensa de la Libre Competencia no son de naturaleza administrativa, pero tampoco constituyen causas civiles, sino una función jurisdiccional penal. Sin embargo, por otra parte, el Tribunal Constitucional no llevó tal afirmación hasta sus últimas consecuencias, sino que observó que el legislador había considerado pertinente remitir el procedimiento seguido ante el Tribunal de Defensa de la Libre Competencia al procedimiento civil y, por esta vía, ha incorporado las garantías propias de éste ${ }^{35}$. De tal forma, consideró que la configuración del derecho a la defensa correspondía a la de cualquier litigante en un procedimiento sujeto al Código de Procedimiento Civil y no a las garantías especiales de las causas criminales, como era el caso de la garantía de no autoincriminación ${ }^{36}$.

En fin, debemos concluir que las infracciones a la legislación sobre protección de la libre competencia han sido configuradas por el legislador, como un "tipo especial de procedimiento" ${ }^{37}$. Recordemos que, como lo ha sostenido el Tribunal Constitucional, el conocimiento de las infracciones a la legislación sobre protección de la libre competencia se encuentra entregado en Chile a un órgano jurisdiccional, y no a un ente administrativo, a diferencia de lo que ocurre en otras legislaciones. Son razones históricas y presupuestarias, por las que hoy se encuentra radicada en el Tribunal

${ }^{32}$ TC Rol No 2381-12 de 20 de agosto de 2013, disponible [en línea]: https:// www.tribunalconstitucional.cl/ver2.php?id=2822], 16º TC Rol No 1448-09, cit. (n. 13), $10^{\circ}$.

${ }^{33}$ TC Rol No 2381-12, cit. (n. 32), 16º; Rodríguez CollaO, Luis, Bases para distinguir entre infracciones criminales y administrativas, en Revista de Derecho de la Pontificia Universidad Católica de Valparaíso 11 (2010).

${ }^{34}$ TC Rol No 1448-09, cit. (n 13), 14º; Rol No 2381-12, cit. (n. 32), 17o.

${ }^{35}$ TC Rol No 2381-12, cit. (n. 32), 33․

${ }^{36}$ TC Rol No 2381-12, cit. (n. 32), 37º. En cuanto a la prohibición de autoincriminación en procedimientos jurisdiccionales no criminales o a actuaciones administrativas, véase también TC Rol No 2897-15 de 4 de julio de 2017, 19º, disponible [en línea]: https://www.tribunalconstitucional.cl/ver2.php?id=3447.

${ }^{37}$ TC Rol No 2381-12, cit. (n. 32), 34º. 
de Defensa de la Libre Competencia, la facultad sancionatoria, además de otras potestades que no son propiamente jurisdiccionales ${ }^{38}$.

Estos motivos impiden que debamos tomar en consideración el precedente establecido en torno al Tribunal de Defensa de la Libre Competencia, al momento de resolver el carácter de las sanciones aplicadas por el SERNAC.

\section{LAS CARACTERÍSTICAS DE LA FUNCIÓN JURISDICCIONAL CIVIL}

La función jurisdiccional podría ser definida desde el punto de vista orgánico como "la ejercida con carácter exclusivo por los jueces y tribunales, aplicando las normas jurídicas en los juicios civiles, penales y contenciosoadministrativos, juzgando de modo inmutable y ejecutando lo juzgado" 39 . Sin embargo, debemos procurar determinar los elementos que configuran la el ejercicio de la función jurisdiccional desde un punto de vista material, por cualquier órgano ${ }^{40}$, partiendo de la idea general que, en teoría, podrían serle atribuidas al órgano administrativo no sólo funciones administrativas sino también legislativas y jurisdiccionales ${ }^{41}$.

En la doctrina del Tribunal Constitucional, la función de los tribunales es ejercer jurisdicción. Esta consiste en el poder-deber que tienen los tribunales para conocer y resolver, por medio del proceso y con efecto de cosa juzgada, los conflictos de intereses de relevancia jurídica que se promuevan, en el orden temporal, dentro del territorio de la República y en cuya solución les corresponda intervenir ${ }^{42}$.

${ }^{38}$ TC Rol No 1448-09, cit. (n. 13), 16º.

${ }^{39}$ Penalva, Ernesto Pedraz, De la jurisdicción como competencia a la jurisdicción como órgano, en Revista de Administración Pública 79 (1976), pp. 145-161.

${ }^{40}$ Este criterio ha sido sostenido en varias ocasiones por el Tribunal Constitucional. TC Rol No 478-06 de 8 de agosto de 2006, 13º, disponible [en línea]: https:// www.tribunalconstitucional.cl/ver2.php?id=151; TC Rol No 1393-09 de 28 de octubre de 2010, 7o , disponible [en línea]: https://www.tribunalconstitucional. cl/ver2.php?id=1601; CоLOMBo, cit. (n. 12), p. 45, según el cual, las autoridades administrativas a las cuales la ley le ha otorgado especialmente el ejercicio de facultades jurisdiccionales son tribunales de justicia.

${ }^{41}$ Gordillo, cit. (n. 5), pp. IX-9; Brewer-Carías, A. R., El concepto de Derecho administrativo en Venezuela, en Revista de Administración Pública 100 (1983), 100, pp. 685-704, p. 694; Brewer-Carías, A. R., Sobre el concepto del Derecho administrativo (Instituto Nacional de Administración Pública (INAP), 2015), p. 15; GonZÁleZ, cit. (n 20), p. 121.

${ }^{42}$ TC Rol 165-93, cit. (n. 14 ), $1^{\circ}$; Rol No 2865, cit. (n. 10), 35\%; Rol No 3594-17, cit. (n. 10), 33; Rol No 346, de 8 de abril de 2002, disponible [en línea]: https://www.tribunalconstitucional.cl/ver2.php?id=274, 43; TC Rol No 606-2006 de 20 de marzo de 2006, 9º; Colombo, cit. (n. 12), p. 41; Colombo Campbell, 
En la sentencia del 18 de enero de 2018 el Tribunal Constitucional analizó la naturaleza de la competencia para dirimir conflictos entre consumidores y proveedores, como un mecanismo de solución de conflictos por un tercero ${ }^{43}$. Un elemento determinante de tales conflictos derivaría de la naturaleza de los contratos que median entre los proveedores comerciantes y los consumidores, tal como sucede en el campo análogo de la libre competencia, a diferencia de otros ámbitos del orden público económico ${ }^{44}$. Finalmente, el Tribunal hizo referencia al efecto de cosa juzgada como un elemento característico de un acto jurisdiccional ${ }^{45}$.

De acuerdo con lo expuesto, podemos centrar nuestro análisis, en torno a tres elementos, que han sido señalados como característicos de la función jurisdiccional, al efecto, la resolución de conflictos entre particulares, el efecto de cosa juzgada de la decisión ${ }^{46}$ y la imparcialidad del órgano. Estos elementos se encuentran implícitos en el texto del artículo 76 de la Constitución Política, el cual alude a "la facultad de conocer de las causas civiles y criminales, de resolverlas y de hacer ejecutar lo juzgado". Desestimaremos sin embargo, los elementos relacionados con el efecto de cosa juzgada ${ }^{47}$ y la imparcialidad del órgano ${ }^{48}$, en cuanto a su idoneidad para servir de

Juan, Protección jurisdiccional de la Constitución: La Declaración Judicial de Inconstitucionalidad, en Revista de Derecho (Valdivia) 12 (2001), 1, p. 15; LÜBBERT, cit. (n. 5), p. 90; Moraga, cit (n. 5), p. 235; Cea, cit. (n. 29), p. 29.

${ }^{43}$ TC Rol No 4012-17-CPR, cit. (n 1), $29^{\circ}$.

${ }_{44}$ TC Rol No 4012-17-CPR, cit. (n 1), 34\%.

${ }^{45}$ TC Rol No 4012-17-CPR, cit. (n 1), $35^{\circ}$.

${ }^{46}$ Véase, con respecto a la cosa juzgada como característica del acto jurisdiccional, TC No Rol 2690 de 6 de agosto de 2015, 10º, disponible [en línea]: https://www. tribunalconstitucional.cl/ver2.php?id=3145.

${ }^{47}$ Un argumento de tal naturaleza reconduciría siempre hacia el criterio orgánico, en razón de que, en contra de los actos de la administración que afecten derechos individuales es procedente el control judicial, en virtud de lo dispuesto en el artículo 38, inciso segundo, de la Constitución. Por tal motivo, no seguiremos el método utilizado por el Tribunal Constitucional al pronunciarse acerca de la naturaleza jurídica de los actos de retención de la Tesorería, en TC Rol No 2865, cit. (n. 10), 35; Rol No 3594-17, cit. (n. 10), 33․ También en ese sentido, el voto en contra de los Ministros señores Carlos Carmona Santander, Gonzalo García Pino y Nelson Pozo, en TC Rol No 4012-17-CPR, cit. (n 1). Tampoco compartimos el criterio del Tribunal Constitucional, que estimó reforzado el carácter jurisdiccional de la sanción impuesta por el SERNAC, en virtud de que, de acuerdo con lo dispuesto en el artículo $50 \mathrm{~S}$ del proyecto, en un juicio posterior, donde se demande alguna indemnización, no podrá discutirse la infracción que ha sido sancionada por el Servicio Nacional del Consumidor mediante resolución firme, en TC Rol No 401217-CPR, cit. (n. 1), $35^{\circ}$.

${ }^{48}$ Véase al respecto, las referencias en la nota 5. 
criterio determinante de la existencia de una función jurisdiccional. En ambos casos se trata sólo de una consecuencia, y no presupuesto, de la existencia de una controversia civil ${ }^{49}$, cuyo desarrollo excedería los límites del presente estudio.

1. La potestad de aplicar las leyes

La Constitución de 1822, inspirada en la Constitución Norteamericana de 1787 y en la Constitución de Cádiz de $1812^{50}$, definía la función del Poder Judicial como "la potestad de aplicar las leyes". La expresión se encontraba contenida en el art. 242 de la Constitución de Cádiz, pasando por casi todos los textos constitucionales españoles del siglo XIX, hasta el art. 91 de la Constitución de $1869^{51}$.

La potestad de aplicar las leyes es entendida en el sentido de aplicación del derecho objetivo en los casos concretos. Si bien la aplicación del derecho también se produce a través de la actividad administrativa, al respecto, se ha precisado que la potestad jurisdiccional no es un mero comportamiento con arreglo a las normas jurídicas, sino la realización en concreto de las reacciones previstas por el ordenamiento para el caso de que el comportamiento no se ajuste a la norma o exista un peligro de infracción de ésta ${ }^{52}$.

Otro elemento diferenciador en el marco de la potestad de aplicar las leyes, se encuentra referido a aplicación sustancial de la ley por el órgano judicial ${ }^{53}$, mientras que las funciones de gobierno se refieren a la esfera de lo decidible, se fundan en la voluntad popular e implican una valoración discrecional o política de los intereses generales ${ }^{54}$. Pero al respecto puede objetarse que, los jueces no son simples funcionarios ejecutores de lo normativamente predispuesto, siendo que, en realidad, todas las normas de un sistema legal obedecen a juicios de valor $\mathrm{y}$, consiguientemente, al

${ }^{49}$ Un criterio distinto es sostenido por Colombo, cit. (n. 12), p. 53.

${ }^{50}$ Zúniga Urbina, Francisco, Corte Suprema y sus competencias. notas acerca de su potestad normativa (Autos Acordados), en Ius et Praxis 4 (1998), 1, p. 222.

${ }^{51}$ Ramos Ortells, Manuel, Aproximación al concepto de potestad jurisdiccional en la Constitución Española, en Anuario de la Facultad de Derecho 3 (1984), p. 420.

${ }^{52}$ Ramos, cit. (n. 51), p. 422; CEA EGAÑA, José Luis, Función jurisdiccional y poder judicial, en Revista Chilena de Derecho (1979), p. 300.

${ }^{53}$ Desde este punto de vista, el concepto de función jurisdiccional se encontraría asociado con una relación de concordancia (no contradicción) entre normas o conjuntos normativos de diverso grado jerárquico. TC Rol No 3028-16 de 15 de noviembre de 2016, 30 disponible [en línea]: https://www.tribunalconstitucional.cl/ ver2.php?id=3351]; TC 2921-15 de 13 de octubre de 2016, 30 [visible en internet: https://www.tribunalconstitucional.cl/ver2.php?id=3341.

${ }^{54}$ Ferrajoli, cit. (n. 20), p. 88; GonZÁlez, cit. (n. 20), p. 91; LÜBberT,, cit. (n. 5), p. 91. 
interpretarlas y aplicarlas a la solución de controversias, la judicatura no debe prescindir de tal axiología ${ }^{55}$.

2. La protección de intereses individuales

Desde el punto de vista de la distinción entre el derecho subjetivo y los mecanismos de protección, la jurisdicción es concebida como garantía de la efectividad del derecho de acción. ${ }^{56} \mathrm{La}$ función jurisdiccional tiene por objeto la constatación y sanción o reparación de la lesión de un derecho subjetivo. ${ }^{57}$ El Tribunal Constitucional ha hecho suya la definición de Couture, en el sentido que, la función jurisdiccional es "la función pública, realizada por órganos competentes del Estado, con las formas requeridas en la ley, en virtud de la cual, por acto de juicio, se determina el derecho de las partes, con el objeto de dirimir sus conflictos y controversias de relevancia jurídica, mediante decisiones con autoridad de cosa juzgada, eventualmente factibles de ejecución" ${ }^{58}$.

Las teorías subjetivas, que afirman la tutela del derecho subjetivo como función específica de la potestad jurisdiccional, pueden ser conectadas con la función de actuación del derecho objetivo, mediante la precisión de que el ordenamiento jurídico privado sólo es infringido y está necesitado en consecuencia de actuación, en la medida en que lo postule el titular del interés privado insatisfecho, porque éste ostenta un poder de disposición que le permite renunciar a la defensa de su interés, sin que esto último sea contrario al propio ordenamiento 59 .

${ }^{55}$ CEA, cit. (n. 52), p. 302. En cuanto al sistema de valores de la Constitución, véase TC Rol No 740, de 18 de abril de 2008, 47․ ID vLex: 58941744, disponible [en línea]: http://jurisprudencia.vlex.cl/vid/-58941744; TC No Rol 2690 de 6 de agosto de 2015, cit. (n. 46); TC Rol No 567-06 de 3 de junio de 2010, 27o, disponible [en línea]: https://www.tribunalconstitucional.cl/ver2.php?id=1386. En cuanto a la discrecionalidad de los jueces, TC Rol 1564-09 de 07 de diciembre de 2010, 330, disponible [en línea]: https://www.tribunalconstitucional.cl/ver2. php?id $=1665$.

${ }^{56}$ GonZÁlez, cit. (n. 20), p. 126

${ }^{57}$ Ferrajoli, L. - Baccelli, L. - de la Vega, A. D. C. - Pisarello, G., Los fundamentos de los derechos fundamentales (Madrid, Trotta, 2001), p. 26; GONZÁLEZ, cit. (n. 20), p. 130; Alcalá-Zamora y Castillo, Niceto, cit. (n. 14), p. 51; Bordalí, cit. (n. 5) y Bordalí Salamanca, Andrés, Análisis crítico de la función e independencia judicial en el Derecho chileno (2007) 57, disponible [en línea]: http://www.expansiva. cl/media/en_foco/documentos/14112007101427.pdf, p. 7.

${ }^{58}$ TC Rol No 1448-09, cit. (n. 13), 13․

${ }^{59}$ Ramos, cit. (n. 51), p. 424. Véase también una relación detallada de las teorías subjetivas y objetivas de la función jurisdiccional en, Pérez-Cruz Martín, Agustín-Jesús, Constitución y poder judicial en Atelier (2015), disponible [en línea]: http://facultad.pucp.edu.pe/derecho/wp-content/uploads/2015/03/ Constituci\%C3\%B3n-y-Poder-Judicial..pdf, pp. 12 ss.; AlCalÁ-Zamora, cit. (n. 
Desde el punto de vista material u objetivo, la función jurisdiccional puede ser definida como la "decisión con fuerza de verdad legal de una controversia entre partes" ${ }^{\prime 0}$. Se trata de la decisión imperativa de contiendas entre partes, determinando el derecho aplicable ${ }^{61}$. La diferencia específica del juicio respecto de la administración reside en una relación de dos partes y un juzgado, una relación asociada con la resolución de un tema de competición ${ }^{62}$.

De tal forma, el ámbito de acción de la función jurisdiccional no está puesto en los intereses generales, sino en los derechos subjetivos, intereses legítimos y posiciones jurídicas que manifiestan los litigantes en el proce$s \mathrm{o}^{63}$, mientras que el ámbito natural donde actúa la administración es el de los intereses generales ${ }^{64}$.

\section{Los procedimientos contenciosos}

La consecuencia en el procedimiento, de la existencia de un conflicto entre partes, se refleja en la configuración legislativa de un procedimiento contencioso. Este elemento fue tomado en consideración por el Tribunal Constitucional, en la calificación de las competencias administrativas atribuidas al Tribunal de Defensa de la Libre Competencia. Observó que en el ejercicio de ellas, el Tribunal de Defensa de la Libre Competencia no conoce de pretensiones procesales originadas en un conflicto de carácter jurídico, sino que por solicitud y no demanda de los interesados, se pronuncia sobre ciertas declaraciones y diligencias que, como es propio en los procedimientos no contenciosos, los particulares no pueden realizar por sí, requiriendo de la intervención del tribunal. ${ }^{65}$ En ejercicio de tales potestades el Tribunal se ciñe a un procedimiento que culminará la dictación de un acto que tendrá la denominación de resolución o un informe ${ }^{66}$.

4. La resolución imperativa de controversias

Finalmente, debemos referirnos a la resolución de controversias, como uno de los elementos que derivan de la finalidad de la jurisdicción, a partir

57), p. 36; Nieva Fenoll, Jordi, Seis conceptos en busca de un objetivo: jurisdicción, acción, proceso, derechos, pena y delito en Política criminal 12 (2017), 23, p. 107.

${ }^{60}$ Gordillo, cit. (n. 5), p. IX-12

${ }^{61}$ Gordillo, cit. (n. 5), p. IX-5; Brewer-Carías, cit. (n. 41), p. 17

${ }^{62}$ Damaska, Mirjan R., Las caras de la justicia y el poder del Estado. Análisis comparado del proceso legal (Santiago, Editorial Jurídica de Chile, 2000), p. 155; Fuenzalida, P. - Valderrama, M., La potestad consultiva del Tribunal de Defensa de la Libre Competencia: jurisdiccional o administrativa?, en Revista Derecho Administrativo Económico 13 (2017), p. 189.

${ }^{63}$ Moraga, cit (n. 5), pp. 235 y 237.

${ }^{64}$ Moraga, cit (n. 5), p. 235.

${ }^{65}$ TC Rol No 1448-09, cit. (n. 13), 16º.

${ }^{66}$ TC Rol No 1448-09, cit. (n. 13), 17\%. 
del concepto de derecho subjetivo. La crítica de esta teoría, ha advertido que la resolución de la controversia puede ser encomendada a órganos no jurisdiccionales, sino de arbitraje o conciliación ${ }^{67}$. Pero, como hemos señalado anteriormente, no es el órgano el elemento idóneo para definir la naturaleza material de la función jurisdiccional ${ }^{68}$.

A los efectos de nuestro estudio, resulta interesante analizar si las vías alternativas de resolución de conflictos comparten la misma naturaleza del acto jurisdiccional. Mientras que el Tribunal Constitucional ha resuelto invariablemente el problema en forma afirmativa ${ }^{69}$, en la doctrina es un tema muy controvertido. La diversidad de criterios, resulta además compleja debido a la pluralidad de vías alternativas de resolución de conflictos y a sus características particulares.

Las diversas posturas se refieren especialmente al elemento de voluntariedad que es propio de tales instituciones. Este criterio se plantea con mayor intensidad en las formas negociadas de solución de conflictos, tales como la negociación y la mediación y, en menor medida en el arbitraje ${ }^{70}$.

${ }^{67}$ Pérez-Cruz, cit. (n. 59), p. 14.

${ }^{68}$ Ejemplos de mediación por órganos administrativos, los encontramos en el ejercicio de la Inspección del Trabajo de mecanismos de conciliación obligatoria, con el objeto de resolver el eventual conflicto individual así como la función de mediación laboral encargada a la Inspección del Trabajo, en materia de conflictos colectivos. Al respecto, Ugarte Cataldo, José Luis, Inspección del trabajo en Chile: vicisitudes y desafios, en Revista Latinoamericana de Derecho Social 6 (2008), p. 193.

${ }^{69}$ Es el caso de la mediación obligatoria en materia de salud (TC Rol No 2042-11 de 10 de julio de $2012,30^{\circ}$, disponible [en línea]: https://www.tribunalconstitucional. cl/ver2.php?id=2465]; las comisiones conciliadora y arbitrales en concesiones de obras públicas (TC Rol No 236-96 de 11 de junio de 1996, 11º, disponible [en línea]: https://www.tribunalconstitucional.cl/ver2.php?id=381, reiterado en TC Rol No 1536-09 de 26 de noviembre de 2009, 6º [visible en internet: https://www. tribunalconstitucional.cl/ver2.php?id=1263]); los Tribunales Arbitrales en materias de Propiedad Industrial TC Rol No 119-91 de 23 de enero de 1991, 7º, disponible [en línea]: https://www.tribunalconstitucional.cl/ver2.php?id=493; de Registro de Variedades Protegidas (TC Rol No 195-94 de 14 de septiembre de 1994, 6º, disponible [en línea]: https://www.tribunalconstitucional.cl/ver2.php?id=421]; de concesiones de bienes fiscales (TC Rol No 360-02 de 17 de septiembre de 2002, 7o, disponible [en línea]: https://www.tribunalconstitucional.cl/ver2.php?id=260]); de servicios de telecomunicaciones (TC Rolo 2191-12 de 16 de mayo de 2012, 19º, disponible [en línea]: https://www.tribunalconstitucional.cl/ver2.php?id=2395).

${ }^{70}$ Véase al respecto, CHocrón Giráldez, Ana María, La exclusividad y la unidad jurisdiccionales como principios constitucionales en el ordenamiento jurídico español, en Boletín mexicano de derecho comparado 38 (2005), 113, p. 667; BARONA VILAR, Silvia, Las ADR en la justicia del siglo xxi, en especial la mediación, en RDUCN. 18 (2011), 1, p. 199. En criterio de Moraga, cit (n. 5), p. 247, en los casos en que la autoridad administrativa que hace de árbitro arbitrador actúa en función 
Mientras que en el juicio la decisión es asumida por un tercero que suple la voluntad de las partes y decide por ellas cuál es la solución que se dará al conflicto, en el caso de la mediación, las partes mantienen el control del proceso de resolución del conflicto en el sentido que son libres para decidir si lo inician, siguen o terminan, y acuerdan por sí mismos, la propia decisión que dará solución al conflicto que los aqueja ${ }^{71}$. Según tal criterio, el elemento de la voluntariedad constituye un importante elemento diferenciador frente al juicio civil, en el cual produce una decisión imperativa de contiendas entre partes.

Sin embargo, estimamos que tales objeciones olvidan que el elemento de voluntad es inherente al concepto del derecho subjetivo ${ }^{72}$, por lo que la disponibilidad de los bienes jurídicos en juego se refleja en no pocas oportunidades en el proceso civil. En sentido inverso, también encontramos una variable intensidad del ejercicio del poder de imperio del juez. El elemento que si permanece invariable, es que se trata, en definitiva, de la participación de un tercero, en la solución de un conflicto intersubjetivo. En la medida en que tal elemento también caracteriza a los mecanismos alternativos, entonces tendríamos que admitir que éstos también constituyen el ejercicio de una función jurisdiccional.

jurisdiccional. También en este sentido, Pérez Ragone, Alvaro J. - Copani, Juan C., Los llamados medios alternativos de resolución de conflictos vistos desde el proceso civil ¿la justa realización del derecho material vs la resolución de conflictos?, en Revista de Derecho de la Pontificia Universidad Católica de Valparaiso 27 (2010), 1, p. 159. Igualmente, en el derecho comparado, véase el art. 116 de la Constitución de Colombia, el cual alude a "la función de administrar justicia"; CCC, C-330/12 disponible [en línea]: http://www.estudiosconstitucionales.com/SENTENCIAS_archivos/c-330_2012. htm; C-961/06, disponible [en línea]: http://www.estudiosconstitucionales.com/ SENTENCIAS_archivos/C-961-06.htm].

${ }^{71}$ Gómez BARBoza, Paulina, La mediacion, una forma alternativa de resolución de conflictos. Su naturaleza, esencia, caracteristicas, estructura, ventajas y desventajas frente a la solución judicial, en Revista de Derecho de la Pontificia Universidad Católica de Valparaíso 20 (2010), p. 382; BARONA, cit. (n. 70), p. 207; Gordillo, cit. (n. 5), pp. IX-5; Brewer-Carías, cit. (n. 41), p. 17. También se alude a la disponibilidad del derecho: Bordali Salamanca, Andrés, Justicia privada, en Revista de Derecho (Valdivia) 16 (2004), o al efecto de cosa juzgada, Jequier Lehuede, Eduardo, La ejecución del acuerdo de mediación en asuntos civiles y comerciales. Una revisión impostergable, en Revista de Derecho (Valdivia) [ 31 (2018), 2, pp. 71-93.

${ }^{72}$ En cuanto a la evolución de la "teoría de la voluntad", EspinOzA, Alexander RIVAS, Jhenny, Ley Orgánica de la Jurisdicción Contencioso-Administrativa. Aspectos Fundamentales ( $3^{\mathrm{a}}$ edición, Caracas, Instituto de Estudios Constitucionales IEC Caracas, 2013), p. 158. 


\section{LAS COMPETENCIAS DEL SERNAC COMO UN TODO SISTEMÁTICO}

El análisis realizado por el Tribunal Constitucional no estuvo referido en forma individual a la naturaleza de cada una de las facultades atribuidas al Servicio Nacional del Consumidor. El Tribunal Constitucional no distinguió en forma separada las funciones de recibir denuncias y reclamaciones, arbitrar conciliaciones, sancionar a los proveedores o adoptar medidas conservadoras y cautelares, sino como un "conjunto de antecedentes, analizados y concatenados entre sí" ${ }^{\prime \prime 3}$, contenidos en disposiciones se vinculan unas con otras como un solo todo sistemático ${ }^{74}$.

Estimamos que, si bien este método podía facilitar el estudio del Proyecto de Ley remitido, en vista de su extensión y profundidad, sin embargo, sólo habría estado justificado, en la medida en que se trate de disposiciones a tal punto vinculadas entre sí, que el análisis individual de cada norma hubiera afectado en su esencia la estructura diseñada por el Legislador. No se aclara en la motivación del fallo, por ejemplo, que las facultades cautelares sean inseparables del procedimiento de conciliación o de multa.

Vista la diversa naturaleza de las facultades atribuidas, la hipótesis de que constituyen un solo todo sistemático sería difícil de sostener, a menos que, como analizaremos en seguida, se afirme que, el tipo de relación jurídica entre proveedores y consumidores constituye una materia inherente a una función jurisdiccional, debido a su naturaleza triangular. De resto, el análisis de conjunto realizado pudo haber llevado al Tribunal a declarar la inconstitucionalidad de atribuciones que, individualmente consideradas, aún hubieran conservado el objetivo perseguido por el Legislador, sin que tuvieran una naturaleza de función jurisdiccional.

Analizaremos por ello la relación jurídica de la protección de los derechos de los consumidores y usuarios, para luego referirnos a la naturaleza jurídica de las facultades atribuidas al SERNAC en el proyecto de ley sometido a conocimiento del Tribunal Constitucional.

1. La protección del consumidor y el usuario

En el análisis de la relación jurídica encontraremos en primer término que la regulación por parte del Proyecto de ley, que modifica la Ley $\mathrm{N}^{\circ}$ 19.496, sobre Protección de los Derechos de los Consumidores, constituye un mecanismo de intervención del estado en el ejercicio del derecho a la libertad económica de los proveedores de servicios o productos ${ }^{75}$. Si bien resulta claro que, el bien jurídico protegido está referido a la defensa

${ }^{73} \mathrm{TC}$ Rol No 4012-17-CPR, cit. (n. 1), 36.

${ }^{74} \mathrm{TC}$ Rol No 4012-17-CPR, cit. (n. 1), $27^{\circ}$.

${ }^{75}$ También en este sentido, el voto concurrente del Ministro señor Cristián Aguilar, en TC Rol No 4012-17-CPR, cit. (n. 1), 5. 
de los consumidores y usuarios, sin embargo, debemos determinar si el legislador ha configurado dicha protección como un conflicto de derecho subjetivo entre derechos e intereses individuales, o simplemente de derecho objetivo en la defensa de intereses generales. Estimamos al efecto que, forma parte de la libertad de configuración del legislador, no sólo la determinación de los bienes jurídicos que pretende cautelar mediante la sanción punitiva ${ }^{76}$, sino en general la definición de los elementos más relevantes del sistema de protección, dentro del marco de los principios y valores de la Constitución ${ }^{77}$.

En términos generales, el proyecto de ley, no sólo se dirige a la protección de los intereses individuales de los consumidores, sino que también tiene por objeto garantizar mercados más transparentes y confiable ${ }^{78}$, en vista de que las relaciones de consumo son transversales a todo el sistema económico y dan vida a todos los mercados ${ }^{79}$. El Tribunal Constitucional ha señalado el impacto social del derecho de protección al consumidor y las particularidades que derivan de la dispar capacidad negocial y de las distintas dificultades que enfrentan los consumidores al momento de hacer efectivos sus respectivos derechos ${ }^{80}$. En la doctrina se advierte además el impacto sobre el orden público económico, por el cual se postula que el desarrollo de la economía y del consumo exige ofrecer confianza a los consumidores $^{81}$.

Lo anterior no significa que la finalidad protectora de la norma se dirija exclusivamente a garantizar el interés general ${ }^{82}$. Por el contrario, la configuración legislativa de la protección de los derechos de los consumidores

${ }^{76}$ TC Rol N² 2402-13 de 26 de noviembre de 2013, disponible [en línea]: https://www.tribunalconstitucional.cl/ver2.php?id=2865, 23; TC Rol No 2897-15 de 4 de julio de 2017, cit. (n. 36), $45^{\circ}$.

${ }^{77}$ Con respecto a la esfera de autonomía del legislador, véase TC Rol № 616-06 de 6 de septiembre de 2007, cit. (n. 18), 30; Cordero, cit. (n. 25), p. 128.

${ }^{78}$ Mensaje No 141-362/ de S.E. la Presidenta de la República con el que inicia un proyecto de ley que modifica la Ley $\mathrm{N}^{\circ} 19.496$, sobre protección de los derechos de los consumidores, de 2 de junio de 2014, disponible [en línea]:: https://www. camara.cl/pley/pdfpley.aspx?prmID=9581\&prmTIPO=INICIATIVA.

${ }^{79}$ Mensaje No 141-362, cit. (n. 78).

${ }^{80}$ TC Rol No 980 de 13 de mayo de 2008, ID vLex: 58941736, disponible [en línea]: http://jurisprudencia.vlex.cl/vid/-58941736, 9º. También en este sentido, el voto en contra de los Ministros señores Carlos Carmona Santander, Gonzalo García Pino y Nelson Pozo en TC Rol No 4012-17-CPR, cit. (n. 1), 36.

${ }^{81}$ Baraona GonZÁlez, Jorge, La regulación contenida en la Ley 19.496 sobre protección de los derechos de los consumidores y las reglas del código civil y comercial sobre contratos: un marco comparativo, en Revista Chilena de Derecho 41 (2014), 2, pp. 381-408.

${ }^{82}$ Este criterio es sostenido por el voto en contra de los Ministros señores Carlos 
ha sido orientada fundamentalmente, hacia la regulación de la relación jurídico-privada de los proveedores y consumidores. Al efecto, la ley reconoce expresamente derechos y deberes básicos del consumidor, así como, derechos específicos del consumidor de productos o servicios financieros (art. 3), mientras que en otras disposiciones reconoce facultades jurídicas en protección de los intereses individuales, tales como la de poner término unilateralmente al contrato (art. $3^{\circ}$ bis) o la de dejar sin efecto contratos de servicios educacionales de nivel superior (art. $3^{\circ}$ ter).

En un resumen parcial, podemos afirmar que, el tipo de relación jurídica entre proveedores y consumidores plantea un conflicto entre intereses individuales. En la medida en que su resolución hubiera sido atribuida a un órgano del estado, podríamos estar en presencia de una función jurisdiccional, debido a su naturaleza triangular. Pero esto aún no es suficiente para afirmar que todas las facultades atribuidas por el legislador al Servicio Nacional del Consumidor compartan tal naturaleza como un todo sistémico, en razón de que, como hemos visto, la protección de los intereses individuales concurre con la finalidad de protección de importantes intereses generales.

2. La defensa del usuario de servicios públicos

En este punto conviene hacer referencia a la precisión de la sentencia bajo estudio, en el sentido que, la protección de los derechos de los consumidores debe ser análogo a la materia de la libre competencia, a diferencia de otros ámbitos del orden público económico, donde se trata de cautelar la observancia de alguna legislación especializada y distinta a la contratación general regida por los códigos Civil y de Comercio, a objeto de asegurar la regularidad y continuidad de determinados servicios de utilidad pública, y que -por eso- podrían ameritar una regulación diferenciada ${ }^{83}$.

El argumento expuesto parece marcar una línea que separa la defensa general del consumidor y de la libre competencia, frente a otros ámbitos del orden público económico, a partir del interés en la protección de la regularidad y continuidad de los servicios públicos. Sin embargo, en el ámbito de la defensa del usuario de servicios públicos esenciales, también encontramos disposiciones que atribuyen a la autoridad administrativa la resolución de conflictos entre intereses individuales. Ejemplo de ello, es la facultad de la Superintendencia de Electricidad y Combustibles, prevista en el art. 3 num. No 17 de la Ley No 18.410, Ley Orgánica de la Superintendencia de Electricidad y Combustibles, de resolver, oyendo

Carmona Santander, Gonzalo García Pino y Nelson Pozo, en TC Rol N 4012-17CPR, cit. (n. 1).

${ }^{83}$ TC Rol No 4012-17-CPR, cit. (n. 1), 34 
a los afectados, los reclamos que se formulen por, entre o en contra de particulares, consumidores y propietarios de instalaciones eléctricas, de gas y de combustibles líquidos, en general, y que se refieran a cualquier cuestión derivada de los cuerpos legales o reglamentarios cuyo cumplimiento le corresponde fiscalizar. Este amplio enunciado permite a la autoridad administrativa constituirse en un árbitro que resuelve conflictos de intereses individuales y no exclusivamente del interés general en la prestación del servicio público, en cuyo caso, tendríamos que afirmar que ejerce una función jurisdiccional.

No corresponde al presente trabajo determinar si la noción de servicio público es o no relevante, desde el punto de vista de la controvertida prohibición constitucional del ejercicio de funciones jurisdiccionales por la administración ${ }^{84}$, o para servir de base a una obligación del legislador de establecer una estructura organizativa y de procedimientos esencialmente distinta. Pero podemos afirmar que no se trata de relaciones jurídicas de distinta naturaleza. Estimamos que corresponde al legislador la valoración de la importancia del interés general en los casos de la protección general del consumidor y en los casos de servicios públicos. En ambos ámbitos encontramos una regulación legislativa, destinada no sólo a proteger intereses generales, sino también intereses individuales, en cuyo caso, resulta preciso revisar cada uno de los mecanismos de protección diseñados por el legislador, para determinar si es de naturaleza administrativa o jurisdiccional.

3. La analogía con la defensa de la libre competencia

Por otra parte, debemos referirnos al carácter análogo que existiría, en criterio del Tribunal Constitucional, entre la defensa del consumidor y la defensa de la libre competencia. En la sentencia del 18 de enero de 2018 el Tribunal Constitucional analizó la naturaleza de la competencia para dirimir conflictos entre consumidores y proveedores, como un mecanismo de solución de conflictos por un tercero ${ }^{85}$. Un elemento determinante de tales conflictos derivaría de la naturaleza de los contratos que median entre

${ }^{84}$ Véase en el derecho argentino, CASSAGNE, J. C., Las facultades jurisdiccionales de los entes reguladores de servicios públicos. El caso "Angel Estrada", en Administración y justicia: un análisis jurisprudencial: liber amicorum Tomás-Ramón Fernández (Civitas, 2012), p. 5; Álvarez, Fernando D., La cuestión de las funciones jurisdiccionales de la Administración Pública. Los tribunales administrativos, en Documentación administrativa (2003), pp. 267-268, disponible [en línea]: https://search.proquest. com/docview/2012126494?pq-origsite=gscholar.], p. 209. En Chile, TC Rol No 176 , cit. (n. 15), 6. Al respecto, con más referencias, Bordalí Salamanca, Andrés, La independencia, cit. (n. 5), p. 209; BORDAlí SALAMANCA, Andrés, La administración pública ante los tribunales de justicia chilenos, en Revista Chilena de Derecho 33 (2006), 1 , pp. 31 y ss.

${ }^{85}$ TC Rol No 4012-17-CPR, cit. (n. 1), $29^{\circ}$. 
los proveedores comerciantes y los consumidores, tal como sucede, según el tribunal, en el campo análogo de la libre competencia ${ }^{86}$.

Si bien es cierto que en ambos casos nos encontramos en el ámbito de la regulación de la economía, en la medida en que tienen a tutelar intereses generales que afectan al consumidor, bien a través de la libre competencia en los mercados, o bien para garantizar mercados más transparentes y confiables ${ }^{87}$, desde el punto de vista de las relaciones de consumo, sin embargo, se plantean diferencias sustanciales en cuanto a la relación jurídica primaria. En el caso de la protección de los derechos de los consumidores, la misma se produce a partir de la regulación de la relación jurídico-privada de los proveedores y consumidores, las cuales dan lugar a una relación conflictiva que se resuelve a través de procedimientos contenciosos, a diferencia de las situaciones que corresponden al Tribunal de Defensa de la Libre Competencia, el cual no conoce de pretensiones procesales originadas en un conflicto de carácter jurídico, sino que se pronuncia sobre procedimientos no contenciosos ${ }^{88}$. La diferencia deriva del tipo de relación jurídica, mientras que en un caso tenemos una relación entre particulares regida por el principio de libre contratación, en el segundo caso, nos encontramos frente a un derecho de protección, sin que preceda necesariamente una relación contractual. Se trata del deber del estado de proteger los intereses del competidor afectado por la conducta contraria a la libre competencia.

En todo caso, no se encuentra predeterminada constitucionalmente, ni se encuentra obligado el legislador a seguir modelos análogos. Por el contrario, le corresponde al legislador un amplio margen de evaluación, dentro de los límites establecidos constitucionalmente en la configuración de las normas de organización y procedimientos que se ajusten a la mejor protección de los intereses en conflicto.

\section{Conclusiones parciales}

Hemos visto que, mientras que un proceso judicial orientado a la resolución de conflictos entre las partes de la relación jurídica tiene por objeto principal la tutela del derecho subjetivo, debe admitirse que al mismo tiempo se resguarda, como efecto secundario, la vigencia del ordenamiento jurídico, esto es, la protección del interés general. Del mismo modo, puede afirmarse que un procedimiento administrativo de fiscalización acerca del cumplimiento objetivo de las normas jurídicas, produce al mismo tiempo, como efecto secundario, la protección de intereses individuales. La imposibilidad material de separar de forma absoluta la protección individual de

\footnotetext{
${ }^{86} \mathrm{TC}^{\mathrm{Rol}} \mathrm{N}^{\circ}$ 4012-17-CPR, cit. (n. 1), 34.

${ }^{87}$ Mensaje No 141-362, cit. (n. 78).

${ }^{88} \mathrm{TC}$ Rol No $1448-09$, cit. (n. 11$), 16^{\circ}$ y $21^{\circ}$.
} 
la protección del interés general es la contrapartida de la imposibilidad de separar por completo la función jurisdiccional de la función administrativa. Sólo podemos distinguir entre una función de protección primaria de intereses individuales, a través de un acto jurisdiccional, frente a una protección primaria del interés general, a través de un acto administrativo.

Esta jerarquización permitiría, por ejemplo, resolver la difícil interrogante de, sí la función fiscalizadora de Dirección del Trabajo tiene o no una naturaleza jurisdiccional. No puede rechazarse de plano que al momento de fiscalizar, tal órgano resuelve conflictos entre las partes del contrato de trabajo. ${ }^{89}$ Sin embargo, en aplicación del criterio que aquí proponemos, la fiscalización y la imposición de sanciones corresponden a una función administrativa y no jurisdiccional, en razón de que su finalidad protectora se dirige en primera línea a la tutela de intereses generales y sólo de modo reflejo a la del interés individual. Distinta sería la situación, si como ocurre en el derecho comparado ${ }^{90}$. la decisión produjera de forma directa la satisfacción del derecho subjetivo, a través de un acto de reparación del daño o de restablecimiento de la situación jurídica.

De acuerdo con lo expuesto, no coincidimos con el fallo del Tribunal Constitucional, en el análisis de conjunto de las relaciones jurídicas del consumo, sino que resulta preciso abordar el análisis de cada una de ellas en particular.

\section{LAS FACULTADES ATRIBUIDAS AL SERNAC}

Analizaremos, de acuerdo con el método propuesto, si las facultades atribuidas al SERNAC en el proyecto de ley sometido a conocimiento del Tribunal Constitucional corresponden a una función administrativa, en razón de que su finalidad protectora se dirige en primera línea a la tutela de intereses generales y sólo de modo reflejo a la del interés individual, o si, por el contrario, la decisión procura de forma directa la satisfacción del derecho subjetivo, a través de un acto de reparación del daño o de restablecimiento de la situación jurídica en cuyo caso deberíamos afirmar su naturaleza jurisdiccional.

${ }^{89}$ Ugarte, cit. (n. 68), p. 201., para quien no se trata de una actuación jurisdiccional, porque su resolución no es definitiva y es modificable, precisamente, por los tribunales de justicia.

${ }^{90}$ Por ejemplo las competencias "cuasi-judiciales" del inspector en el derecho colombiano, para decidir sobre las solicitudes de despido de trabajadoras en estado de gravidez o de trabajadores discapacitados. Al respecto, Molina, Carlos Ernesto, La inspección de trabajo en Colombia, en Revista Latinoamericana de Derecho Social 6 (2008), p. 78. 


\section{La facultad de multar a los proveedores}

Aun cuando en el voto autónomo del Ministro Señor Juan José Romero Guzmán ${ }^{91}$ se sostiene que no hay controversia sobre la posibilidad de que un órgano administrativo pueda sancionar, lo cierto es que, en el voto de la mayoría, la facultad de multar a los proveedores fue calificada como una función jurisdicción ${ }^{92}$. De tal forma el Tribunal declaró inconstitucionales, las facultades del Servicio Nacional del Consumidor de tramitar y resolver los procedimientos sancionatorios e imponer las sanciones correspondientes por infracción a la normativa de protección de los derechos de los consumidores, previstos en el proyecto bajo el $\mathrm{N}^{\circ} 52$, letra a); de iniciar de oficio el procedimiento administrativo sancionatorio, o por denuncia, una vez que hayan fracasado las instancias de mediación y conciliación $\left(\mathrm{N}^{\circ} 33\right)$, entre otras.

Hemos visto que, a diferencia de los fallos en materia de libre competencia, el análisis del Tribunal Constitucional no se encuentra referido a la calificación de la multa como una sanción criminal, sino como el ejercicio de una función jurisdiccional en el marco de una causa civil. Sin embargo, dado que hemos descartado el tratamiento del caso como un todo sistémico derivado de la naturaleza de la relación jurídica entre proveedores y consumidores, debemos determinar si la potestad sancionatoria del SERNAC había sido concebida con la finalidad primaria de proteger los derechos subjetivos de los consumidores.

Se podría afirmar que no se trata de una simple potestad sancionatoria de la administración, sino que, al sujetar su ejercicio a la satisfacción de los intereses individuales del consumidor, se transforma en un mecanismo de resolución de un conflicto entre particulares. En favor de este argumento, podría señalarse que el perjuicio causado a los derechos de los consumidores es relevante para la determinación de la proporcionalidad de la sanción, de acuerdo con la gravedad del daño causado o el riesgo a que quedó expuesta la víctima o la comunidad y que, del mismo modo, su reparación efectiva constituye una circunstancia atenuante (art. 24 de la ley).

Debe considerarse que esta objeción es sólo parcialmente válida, en razón de que, como lo disponía el proyecto de ley, el procedimiento administrativo sancionatorio también podría iniciarse de oficio, en cuyo caso no se hubiera planteado un conflicto entre particulares. A ello se agrega el interés general, cuya protección se realiza a través del efecto preventivo de la sanción ${ }^{93}$. Su justificación se atribuye al interés público en la regula-

${ }^{91}$ Consid. $3^{\circ}$, en TC Rol No 4012-17-CPR, cit. (n. 1).

${ }^{92}$ TC Rol No 4012-17-CPR, cit. (n. 1), 31 .

${ }^{93}$ En el voto autónomo del Ministro Señor Juan José Romero Guzmán, se alude a la función disuasoria de la imposición de multas, en TC Rol No 4012-17-CPR, cit. 
ción de las condiciones que se exigen para operar en el mercado, en razón de que los consumidores no cuentan con la capacidad y los medios para determinar la calidad de los productos y servicios que se les ofrecen, y el mercado tampoco puede imponer tales condiciones ${ }^{94}$.

Finalmente, tal como lo indicó el propio Tribunal Constitucional, con la imposición de la multa, no se busca beneficiar ni siquiera a los consumidores, dado que todas las multas van en beneficio fiscal ${ }^{95}$, tal como lo disponía el proyecto de ley, en el art. 50 Ñ, declarado inconstitucional. En efecto, la multa no tiene un efecto reparatorio, como el que corresponde a la acción de indemnización de perjuicios ${ }^{96}$.

De tal forma, que la protección de los derechos subjetivos de los consumidores sólo se hubiera producido como un efecto indirecto o reflejo de la multa y no como un efecto primario, lo cual nos permite concluir, de acuerdo con lo expuesto anteriormente, que la potestad sancionatoria del SERNAC, prevista en el proyecto de ley, no constituye el ejercicio de una función jurisdiccional, en razón de que no comprende la resolución de conflictos de intereses de relevancia jurídica.

2. La facultad de mediación

Recordemos que, la sentencia bajo análisis declaró inconstitucionales las disposiciones que permitían al SERNAC constituirse en instancia de mediación y arbitrar una audiencia obligatoria de conciliación (artículo $1^{\circ}$, $N^{\circ} 33$, del proyecto de ley). La disposición permitía promover un acuerdo voluntario, a partir de las alternativas propuestas por el proveedor, con el carácter de transacción extrajudicial, o bien una audiencia obligatoria de conciliación, en base a bases concretas formuladas por el SERNAC ${ }^{97}$.

De acuerdo con los criterios de delimitación que hemos señalado, debemos determinar si la facultad de mediación atribuida en el proyecto de ley constituye el ejercicio de una función jurisdiccional, esto es, si su finalidad protectora se dirige en primera línea a la tutela de intereses individuales y sólo de modo reflejo a la del interés general.

(n. 1), 15․ Sobre la teoría de la disuasión, véase BEnsusán, Graciela, La Inspección del Trabajo en América Latina: teorias, contextos y evidencias en Estudios sociológicos (2009), p. 994.

${ }^{94}$ Cordero, cit. (n. 25), p. 126.

${ }^{95}$ TC Rol No 4012-17-CPR, cit. (n. 1), 41‥

${ }^{96}$ También en este sentido, el voto en contra de los Ministros señores Carlos Carmona Santander, Gonzalo García Pino y Nelson Pozo, en TC Rol N 4012-17CPR, cit. (n 1).

${ }^{97}$ Una postura distinta fue sostenida en TC Rol No 251 de 27 de enero de 1997, $8^{\circ}$. En el mismo sentido, el voto en contra de los Ministros señores Carlos Carmona Santander, Gonzalo García Pino y Nelson Pozo, en TC Rol N 4012-17-CPR, cit. (n 1$), 4^{\circ}$. 
Estimamos que, en la medida en que tal procedimiento procura la satisfacción de las pretensiones del consumidor, resulta claro que tiene una finalidad primaria de protección de derechos subjetivos, que prevalece frente a la función de defensa del orden jurídico objetivo. Ya hemos tenido oportunidad de precisar que la mediación comparte con el juicio civil que ambos procuran la resolución de controversias. Además el elemento de la voluntariedad no constituye un elemento diferenciador, que sea determinante de la naturaleza del acto.

En el caso del procedimiento de mediación a cargo del SERNAC propuesto en el proyecto de ley, no encontramos elementos que permitan llegar a un resultado distinto, en el sentido que la mediación allí establecida constituye una facultad jurisdiccional.

3. Las potestades de imperio

La sentencia bajo análisis estableció la calidad de ley orgánica constitucional de aquellas normas que facultaban al Servicio Nacional del Consumidor la potestad de resolver con imperio, entre otras materias, el cese de la conducta dañosa de intereses colectivos o difusos; el cálculo de indemnizaciones para los consumidores o la determinación de cautela del cumplimiento del acuerdo. En criterio del Tribunal, tales normas radican potestades jurisdiccionales en el Servicio Nacional del Consumidor, en razón de que disciplinan la solución de conflictos por un tercero ${ }^{98}$, a diferencia del régimen actual, en el que corresponde a los juzgados competentes la corrección de las infracciones a la normativa de que se trata ${ }^{99}$.

Según el fallo, el proyecto controlado, implica que el Servicio Nacional del Consumidor pueda ordenar el cese de las conductas infractoras, la restitución de los cobros que le parezcan improcedentes, así como adoptar indeterminadas medidas para evitar supuestas infracciones futuras (artículo $50 \mathrm{~N}$ ), al modo de una sentencia que acoge una acción de amparo, y en que un juez cumple las funciones conservadoras que le atribuye el artículo $3^{\circ}$ del Código Orgánico de Tribunales ${ }^{100}$.

El artículo $50 \mathrm{~N}$ del proyecto de ley disponía que, la resolución que ponga término al procedimiento, junto con resolver el asunto al que este se refiera, podría ordenar una o más de las siguientes medidas: $a$ ) el cese de la o las conductas infractoras; $b$ ) la imposición de las multas contempladas en la presente ley; $c$ ) para las empresas proveedoras comprendidas en la clasificación del inciso segundo del artículo $2^{\circ}$ de la ley $\mathrm{N}^{\circ} 20.416$, que no sean reincidentes, una capacitación en los derechos y deberes de los

\footnotetext{
${ }^{98}$ TC Rol No 4012-17-CPR, cit. (n. 1), $29^{\circ}$.

${ }^{99} \mathrm{TC}^{\mathrm{Tol}} \mathrm{N}^{\circ}$ 4012-17-CPR, cit. (n. 1), $33^{\circ}$.

${ }^{100} \mathrm{TC}$ Rol No 4012-17-CPR, cit. (n. 1), 35.
} 
consumidores; d) la restitución de los cobros que hubieren tenido lugar con infracción a la presente ley, con reajustes e intereses. En la misma resolución debía señalarse la modalidad en que el infractor deberá realizar las restituciones que correspondan y los plazos de que dispondrá al efecto. Una vez producida la restitución, no sería procedente el ejercicio de acciones judiciales que tengan por finalidad el mismo propósito, sin perjuicio de las acciones de indemnización de perjuicios por los daños causados.

De acuerdo con los criterios de delimitación que hemos señalado, debemos señalar que, en el caso de procedimientos iniciados por denuncia, las facultades de intervención contenidas en el citado artículo $50 \mathrm{~N}$, permiten la satisfacción de las pretensiones del consumidor, por lo que tiene una finalidad primaria de protección de derechos subjetivos, que prevalece frente a la función de defensa del orden jurídico objetivo. Por tales motivos, estimamos que las facultades mencionadas tienen efectivamente un carácter de acto jurisdiccional y no administrativo.

\section{ConClusiones finales}

La actuación de la administración pública puede ser definida a través de un criterio residual, frente a las demás funciones del estado y la protección de intereses generales, mientras que, a los efectos de nuestro estudio, la función jurisdiccional civil, excluida la referida a controversias penales y entre particulares y el Estado o entre los poderes públicos, se caracteriza por la potestad de aplicar las leyes en el caso de que el comportamiento no se ajuste a la norma o exista un peligro de infracción de ésta, con la finalidad de brindar protección a los intereses individuales, a través de un procedimiento contencioso, por un tercero con poder de imperio.

Hemos visto que, ante la imposibilidad material de separar de forma absoluta la protección individual de la protección del interés general, sólo podemos distinguir entre una función de protección primaria de intereses individuales, a través de un acto jurisdiccional, frente a una protección primaria del interés general, a través de un acto administrativo.

La aplicación al caso concreto, permite afirmar que, la facultad de multar a los proveedores atribuida al SERNAC, no tiene un efecto reparatorio, como el que corresponde a la acción de indemnización de perjuicios, lo cual nos permite concluir que no constituye el ejercicio de una función jurisdiccional.

Un resultado distinto corresponde a la facultad de mediación, así como, a la potestad de resolver con imperio, entre otras materias, el cese de la o las conductas infractoras o la restitución de los cobros que hubieren tenido lugar con infracción a la presente ley, con reajustes e intereses. En 
la medida en que tienen una finalidad primaria de protección de derechos subjetivos, que prevalece frente a la función de defensa del orden jurídico objetivo, estas facultades tienen efectivamente un carácter jurisdiccional y no administrativo.

\section{BIBLIOGRAFÍA}

Alcalá-Zamora y Castillo, Niceto, Notas relativas al concepto de jurisdicción, en Estudios de Teoría General e Historia del Proceso (1945-1972) (México D. F., Universidad Nacional Autónoma de México, 1992), I.

Álvarez, Fernando D., La cuestión de las funciones jurisdiccionales de la Administración Pública. Los tribunales administrativos, en Documentación administrativa (2003), disponible [en línea]: https://search.proquest.com/docview/2012126494?pqorigsite $=$ gscholar.

Aróstica Maldonado, Iván, Algunos problemas del Derecho administrativo penal, en Revista de Derecho, 71-81 (1987), disponible [en línea]: http://www.revistadederecho.com/pdf.php?id=2311.

BARAONA GONZÁLEZ, Jorge, La regulación contenida en la Ley 19.496 sobre protección de los derechos de los consumidores y las reglas del Código Civil y Comercial sobre contratos: un marco comparativo, en Revista Chilena de Derecho 41 (2014), 2.

Barona Vilar, Silvia, Las ADR en la justicia del siglo xxi, en especial la mediación, en RDUCN. 18 (2011), 1.

Bensusán, Graciela, La Inspección del Trabajo en América Latina: teorías, contextos y evidencias, en Estudios sociológicos (2009).

BOetTiger Philipps, Camila, El derecho administrativo sancionador en la jurisprudencia del Tribunal Constitucional, en Revista Actualidad Jurídica 20 (2009).

Bordalí Salamanca, Andrés, Análisis crítico de la función e independencia judicial en el Derecho chileno (2007), disponible [en línea]: http://www.expansiva.cl/media/ en_foco/documentos/14112007101427.pdf.

Bordalí Salamanca, Andrés, El derecho fundamental a un tribunal independiente e imparcial en el ordenamiento jurídico chileno, en Revista de Derecho de la Pontificia Universidad Católica de Valparaíso 33 (2009).

Bordalí Salamanca, Andrés, Justicia privada, en Revista de Derecho (Valdivia) 16 (2004).

Bordalí Salamanca, Andrés, La administración pública ante los tribunales de justicia chilenos, en Revista Chilena de Derecho 33 (2006), 1.

Bordalí Salamanca, Andrés, La doctrina de la separación de poderes y el poder judicial chileno, en Revista de Derecho (Valparaíso) 30 (2008).

Bordalí Salamanca, Andrés, La independencia de los jueces en la aplicación de la ley dentro de la organización judicial chilena, en Revista Chilena de Derecho 40 (2013), 2.

Bordalí Salamanca, Andrés, Organización judicial en el derecho chileno: Un poder fragmentado, en Revista Chilena de Derecho 36 (2009), 2.

Brewer-Carías, A. R., Sobre el concepto del Derecho administrativo (Instituto Nacional de Administración Pública, INAP, 2015).

Cabrera Delgado, José Manuel, Duplicidad sancionadora en el ámbito administrativo y penal, en Avances en Supervisión Educativa 22 (2014). 
Cassagne, Juan C., Las facultades jurisdiccionales de los entes reguladores de servicios públicos. El caso "Angel Estrada", en Administración y Kusticia: un análisis jurisprudencial: liber amicorum Tomás-Ramón Fernández (Madrid, Civitas, 2012).

Cea Egaña, José Luis, Función jurisdiccional y poder judicial, en Revista Chilena de Derecho (1979).

Cea Egaña, José Luis, Derecho Constitucional Chileno (Santiago, Ediciones UC, 2008), IV.

Cea Egaña, José Luis, La igual proteccion de los derechos, en Revista Chilena de Derecho 9 (1982).

Colombo Campbell, Juan, La Jurisdicción en el Derecho Chileno (Santiago, Editorial Jurídica de Chile, 1991).

Colombo Campbell, Juan, Protección jurisdiccional de la Constitución: La Declaración Judicial de Inconstitucionalidad, en Revista de Derecho (Valdivia) 12 (2001), 1.

Cordero Quinzacara, Eduardo, Concepto y naturaleza de las sanciones administrativas en la doctrina y jurisprudencia chilena, en Revista de Derecho (Coquimbo) 20 (2013), 1.

Cordero Quinzacara, Eduardo - Aldunate Lizana, Eduardo, Las bases constitucionales de la potestad sancionadora de la Administración, en Revista de Derecho (Valparaíso) 39 (2012).

Cordero Quinzacara, Eduardo, Sanciones administrativas y mercados regulados, en Revista de Derecho (Valdivia) 26 (2013), 1.

CORDERO QUINZACARA, Eduardo, Los principios que rigen la potestad sancionadora de la Administración en el derecho chileno, en Revista de Derecho (Valparaiso) 42 (2014).

Couso, Jaime, Autoria y participación en el derecho sancionatorio administrativo. Hacia una topografia del problema en Ius et Praxis 24 (2018), 1.

Chocrón Giráldez, Ana María, La exclusividad y la unidad jurisdiccionales como principios constitucionales en el ordenamiento jurídico español, en Boletín mexicano de derecho comparado 38 (2005) 113.

DamasKa, Mirjan R., Las caras de la justicia y el poder del Estado. Análisis comparado del proceso legal (Santiago, Editorial Jurídica de Chile, 2000).

EnTEICHE Rosales, Nicolás, Ley No 20.322: avances y desafios respecto de la inspección y sanción de infracciones administrativas en materia tributaria, en Revista Actualidad Jurídica 26 (2012).

Espinoza, Alexander - Rivas, Jhenny, Ley Orgánica de la Jurisdicción ContenciosoAdministrativa. Aspectos Fundamentales (3a edición, Caracas, Instituto de Estudios Constitucionales IEC Caracas, 2013).

Ferrajoli, L. - Baccelli, L. - de la Vega, A. D. C. - Pisarello, G., Los fundamentos de los derechos fundamentales (Madrid, Trotta, 2001).

FERRAJOli, Luigi, El papel de la función judicial en el Estado de Derecho. Jurisdicción y argumentación en el Estado constitucional de derecho, en Miguel CARBONELL, J. et al (coord.), Jurisdicción y argumentación en el estado constitucional de derecho (México D. F., Universidad Nacional Autónoma de México, Instituto de Investigaciones Jurídicas, 2005).

Fuenzalida, P. - Valderrama, M., La potestad consultiva del Tribunal de Defensa de la Libre Competencia: jurisdiccional o administrativa?, en Revista Derecho Administrativo Económico13 (2017). 
Gómez Barboza, Paulina, La mediación, una forma alternativa de resolucion de conflictos. su naturaleza, esencia, caracteristicas, estructura, ventajas y desventajas frente a la solución judicial, en Revista de Derecho de la Pontificia Universidad Católica de Valparaíso 20 (2010).

GonZÁlez Álvarez, Roberto, El nuevo paradigma de la garantía de la jurisdicción, en Ars Boni et Aequi 10 (2014), 1.

Gordillo, Agustín, Tratado de derecho administrativo y obras selectas: Parte general (Buenos Aires, Fundación de Derecho Administrativo, 2017), I.

JEQUIER LEHUEDE, Eduardo, La ejecución del acuerdo de mediación en asuntos civiles y comerciales. Una revisión impostergable, en Revista de Derecho (Valdivia) 31 (2018), 2.

Letelier, Raúl, Garantías penales y sanciones administrativas, en Política Criminal 12 (2017), 24.

LÜBBERT Álvarez, Valeria, El derecho a no ser juzgado por comisiones especiales: análisis crítico de jurisprudencia, en Revista de Estudios de la Justicia 15 (2011).

MaYer, Otto, Deutsches Verwaltungsrecht (Leipzig, Verlag von Duncker \& Humblot, 1895), I.

Molina, Carlos Ernesto, La Inspección de Trabajo en Colombia, en Revista Latinoamericana de Derecho Social 6 (2008).

Moraga Klenner, Claudio, :Existen en Chile procedimientos administrativos que presentan, también, una naturaleza jurisdiccional?, en Derecho PUCP 68 (2011).

Nieva FenOlL, Jordi, Seis conceptos en busca de un objetivo: jurisdicción, acción, proceso, derechos, pena y delito, en Política criminal 12 (2017), 23.

Penalva, Ernesto Pedraz, De la jurisdicción como competencia a la jurisdicción como órgano, en Revista de Administración Pública 79 (1976) 79.

Pérez-Cruz Martín, Agustín-Jesús, Constitución y poder judicial, en Atelier (2015).

Pérez Ragone, Alvaro J. - CopAni, Juan C., Los llamados medios alternativos de resolución de conflictos vistos desde el proceso civil ¿la justa realización del derecho material vs la resolución de conflictos?, en Revista de Derecho de la Pontificia Universidad Católica de Valparaíso 27 (2010).

Ramos Ortells, Manuel, Aproximación al concepto de potestad jurisdiccional en la Constitución Española, en Anuario de la Facultad de Derecho 3 (1984).

Rodríguez Collao, Luis, Bases para distinguir entre infracciones criminales y administrativas, en Revista de Derecho de la Pontificia Universidad Católica de Valparaíso 11 (2010).

Román Cordero, Cristian, El castigo en el Derecho Administrativo, en Derecho y Humanidades 16 (2010), 1.

Silva Cimma, Enrique, Derecho Administrativo chileno y comparado. Introducción y fuentes (5a edición. Santiago, Editorial Jurídica de Chile, 2009).

Soto Kloss, Eduardo, Derecho administrativo. Temas fundamentales ( $3^{\mathrm{a}}$ edición, Santiago, Abeledo Perrot, LegalPublishing-Thomson Reuters, 2012).

Sото Kloss, Eduardo, Derecho Administrativo Penal. Notas para el estudio de la potestad sancionadora de la Administración, en Boletín de Investigaciones (Santiago, Facultad de Derecho, Pontificia Universidad Católica de Chile).

Ugarte Cataldo, José Luis, Inspección del Trabajo en Chile: vicisitudes y desafíos, en Revista Latinoamericana de Derecho Social 6 (2008).

VAN WeEzel, Alex, Sobre la necesidad de un cambio de paradigma en el derecho sancionatorio administrativo, en Política Criminal 12 (2017). 
VON MÜNCH, Ingo, Verwaltung und Verwaltungsrecht im demokratischen und sozialen Rechtsstaat, en ERICHSEN -MARTENS (coord.), Allgemeines Verwaltungsrecht (Walter de Gruyter GmbH \& Co KG, 2016).

ZÚNIIGa Urbina, Francisco, Autonomías constitucionales e instituciones contramayoritarias (a propósito de las aporías de la "democracia constitucional"), en Ius et Praxis 13 (2007), 2.

ZúNiga Urbina, Francisco, Corte Suprema y sus competencias. Notas acerca de su potestad normativa (Autos Acordados), en Ius et Praxis 4 (1998), 1. 